\title{
Imaturos de Chrismopteryx undularia (Blanchard) (Lepidoptera, Geometridae)
}

\author{
Héctor A. Vargas ${ }^{1}$, Olaf H. H. Mielke², Mirna M. Casagrande² \& Luis E. Parra ${ }^{3}$
}

\begin{abstract}
12Departamento de Recursos Ambientales, Facultad de Ciencias Agronómicas, Universidad de Tarapacá, Casilla 6-D, Arica, Chile. havargas@uta.cl
${ }^{2}$ Laboratório de Estudos de Lepidoptera Neotropical, Departamento de Zoologia, Universidade Federal do Paraná. Caixa Postal 19020, 81531-980 CuritibaPR, Brasil. Pesquisadores CNPq.omhesp@ufpr.br; mibras@ufpr.br

${ }^{3}$ Departamento de Zoología, Facultad de Ciencias Naturales y Oceanográficas, Universidad de Concepción, Casilla 160-C, Concepción, Chile. luparra@udec.cl
\end{abstract}

\begin{abstract}
Immatures of Chrismopteryx undularia (Blanchard) (Lepidoptera, Geometridae). Egg, larva and pupa of Chrismopteryx undularia (Blanchard, 1852) (Lepidoptera, Geometridae, Larentiinae) are described and illustrated.
\end{abstract}

KEYWORDS. Larentiinae; morphology; Neotropical.

RESUMO. Imaturos de Chrismopteryx undularia (Blanchard) (Lepidoptera, Geometridae). Ovo, larva e pupa de Chrismopteryx undularia (Blanchard, 1852) (Lepidoptera, Geometridae, Larentiinae) são descritos e ilustrados.

PALAVRAS-CHAVE. Larentiinae; morfologia; Neotropical.

Geometridae é a segunda família mais diversa de Lepidoptera, com mais de 20.000 espécies descritas (Heppner 1991; Gaston et al. 1995; Scoble 1995, 1999). Aproximadamente 40\% são Neotropicais (Heppner 1991).

Aspectos morfológicos dos estágios imaturos de Lepidoptera são reconhecidamente importantes para a taxonomia e sistemática do grupo (ver MacKay 1968; Stehr 1987; Bolte 1990; Choi 1997; Blaik \& Malkiewicz 2003; Sihvonen 2005). No entanto, a maioria das espécies de Geometridae do neotrópico é conhecida apenas pelas descrições originais e pelo material tipo. Consequentemente, estudos acerca da morfologia e bionomia dos estágios imaturos e adultos dos geometrídeos Neotropicais são escassos (e.g. Rindge 1973; Herbulot 1993; Landry \& Rindge 1995; Scoble \& Krüger 2002; Marconato \& Dias 2004).

Chrismopteryx Prout, 1910 possui seis espécies: três para a Argentina e três para o Chile (Scoble 1999), sendo que não existe nenhuma informação publicada sobre os estágios imaturos deste gênero.

Chrismopteryx undularia (Blanchard, 1852) (Figs. 1-2) ocorre no Chile e sua distribuição geográfica está limitada à localidade-tipo de Coquimbo, Chile. Recentemente, foram coletadas larvas em folhas de Bougainvillea glabra Choisy (Nyctaginaceae) no vale de Azapa, no litoral norte do Chile. Tendo em vista a escassez de informações sobre morfologia externa dos imaturos de Geometridae na região Neotropical, o presente trabalho descreve a morfologia externa dos imaturos desta espécie.

\section{MATERIAL E MÉTODOS}

Fêmeas adultas de C. undularia foram coletadas no vale de Azapa (18 34'S; $70^{\circ} 00^{\prime} \mathrm{W}$ ), Província de Arica, Chile, e posteriormente acondicionadas em sacolas plásticas com folhas de B. glabra. As larvas foram acompanhadas individualmente em frascos de vidro e o alimento era reposto diariamente. Para cada indivíduo foi registrada a data de início de cada um dos estágios. As análises morfológicas foram baseadas em pelo menos 20 indivíduos de cada estágio conservados em álcool $70 \%$. As larvas foram previamente imersas em água fervente.

As ilustrações foram preparadas com auxílio de um microscopio e um estereomicroscópio equipado com câmara clara, enquanto que aspectos ultraestruturais foram observados em um microscópio eletrônico de varredura. As medidas que acompanham as descrições foram feitas com ocular graduada. Para estudo da morfologia das larvas e pupas, os espécimes foram tratados com $\mathrm{KOH}(10 \%)$. Para o estudo da quetotaxia o tegumento foi esticado e montado entre lâmina e lamínula. Alguns espécimes foram montados com glicerina e outros com bálsamo de Canadá, como meio de inclusão. Espécimes vouchers estão depositados na Coleção Entomológica Pe. J.S. Moure, Departamento de Zoologia, Setor de Ciências Biológicas, Universidade Federal do Paraná, Curitiba, Brasil (DZUP); na Colección Entomológica de la Universidad de Tarapacá, Arica, Chile (IDEA) e no Museo Nacional de Historia Natural de Santiago, Santiago, Chile (MNNC). Para 
as descrições, foram seguidas as terminologias de Hinton (1946), Salkeld (1983), Stehr (1987), Blaik \& Malkiewickz (2003) e Duarte et al. (2005).

\section{RESULTADOS}

\section{Descrições}

Ovo (Figs. 3-6). Subcilíndrico; branco no momento da oviposição, amarelo claro após dois a três dias, cinza esbranquiçado antes da eclosão; eixo micropilar paralelo ao substrato; cório transparente permite observar a larva em desenvolvimento, esculpido em sua maioria por células hexagonais e algumas pentagonais (Figs. 3, 4); área micropilar com quatro a cinco aberturas micropilares (Fig. 5); roseta micropilar com oito a onze células alongadas basalmente abertas e estreitas, com a margem distal arredondada; aerópilas circulares nos vértices das células poligonais (Fig. 6).

Medidas. Diâmetro médio 0,69 mm $(0,68-0,70 \mathrm{~mm})$; comprimento médio $0,83(0,81-0,84 \mathrm{~mm})$.

Duração. 5-7 dias.

Primeiro ínstar (Figs. 7-31). Cabeça castanho-clara com algumas manchas castanho-escuras; tórax e abdome esbranquiçados imediatamente após eclosão, verde oliváceo após a alimentação; pináculas, cerdas táteis e placas protorácica, anal, subanal e aquelas esclerotinizadas dos larvópodos de coloração castanha.
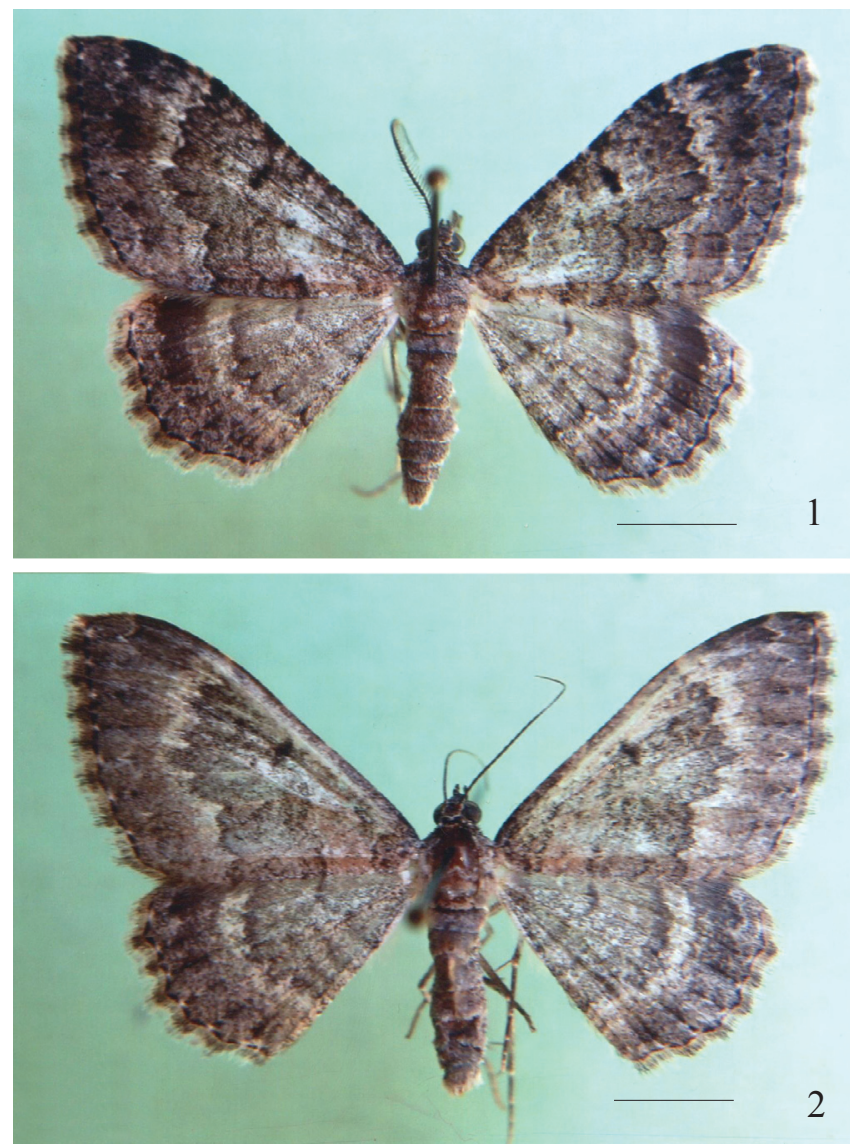

Figs. 1-2. Adultos de Chrismopteryx undularia, vista dorsal. 1, macho; 2, fêmea. Escala: $5 \mathrm{~mm}$.
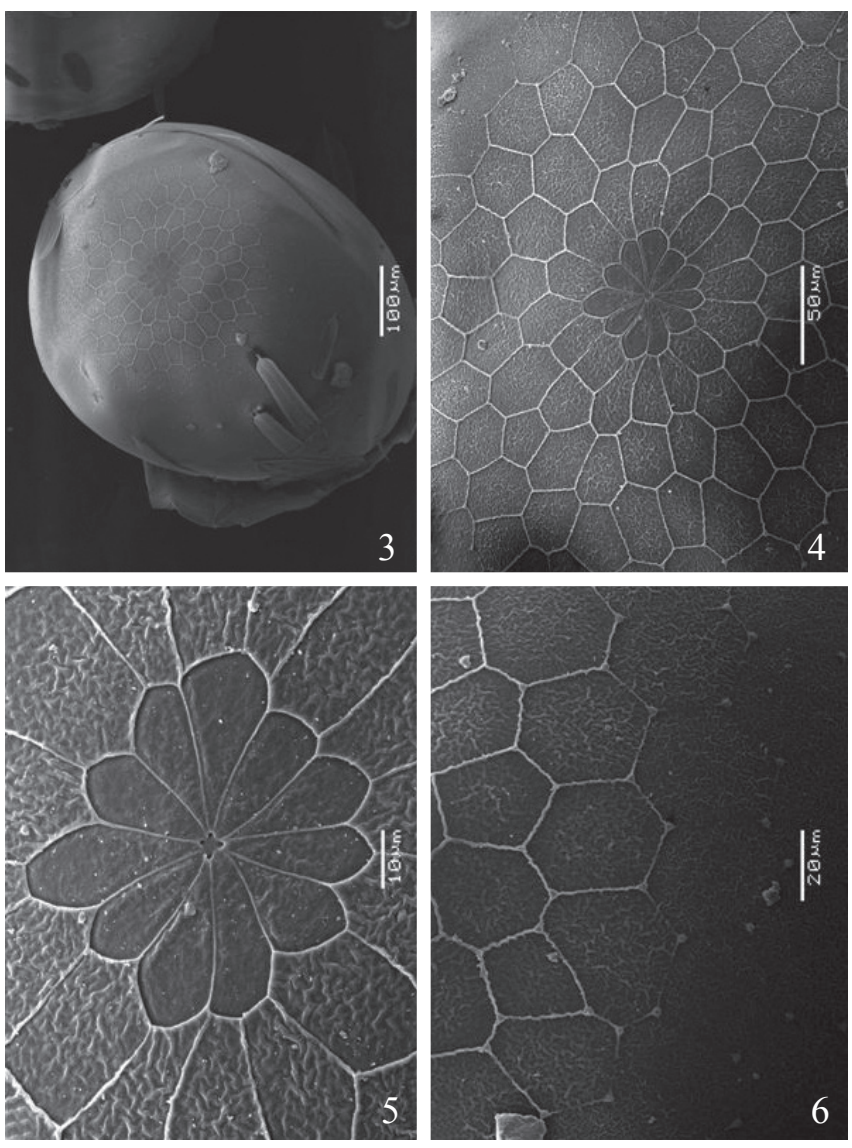

Figs. 3-6. Ovo de Chrismopteryx undularia. 3, área micropilar; 4, roseta micropilar e células poligonais; 5 , roseta micropilar com quatro aberturas micropilares; 6 , aerópilas nos vértices das células poligonais.

Cabeça (Figs. 7-9, 11-19). Hipognata, finamente rugosa (Fig. 7); cerdas táteis com ápice agudo, similares em comprimento (Figs. 7, 11-12); sutura epicranial menor que a metade das suturas adfrontais (Fig. 11); frontoclípeo (Fig. 11) triangular, margem ventral ligeiramente côncava; anteclípeo membranoso, ventral ao frontoclípeo e dorsal ao labro. Seis estemas (Figs 7, 12) circulares, posteriores ao alvéolo antenal; estemas 1-5 em semicírculo, estema 6 entre os estemas 1 e 5, formando uma linha reta. Antenas (Figs. 7, 13) triarticuladas, inseridas no alvéolo antenal membranoso, entre as mandíbulas e a área dos estemas; artículo proximal anular, com a margem proximal oblíqua; artículo mediano anular e de tamanho similar ao proximal; artículo distal pequeno, cilíndrico, diâmetro menor que a metade do mediano. Peças bucais mastigadoras. Labro (Figs. 14-15) sub-retangular, com a margem distal fendida no centro; superfície externa com doze cerdas e seis poros; superfície interna com espinhos dentiformes em dois grupos, de três cada, próximos à margem distal, outros espinhos abundantes e pequenos na área centro-basal. Mandíbulas (Fig. 16) com bordo cortante serrilhado (seis dentes, os dois medianos com pequenos processos na base); duas cerdas na superfície externa, comprimento da cerda distal quase a metade da proximal; duas carenas na superfície interna. Maxilas (Figs. 

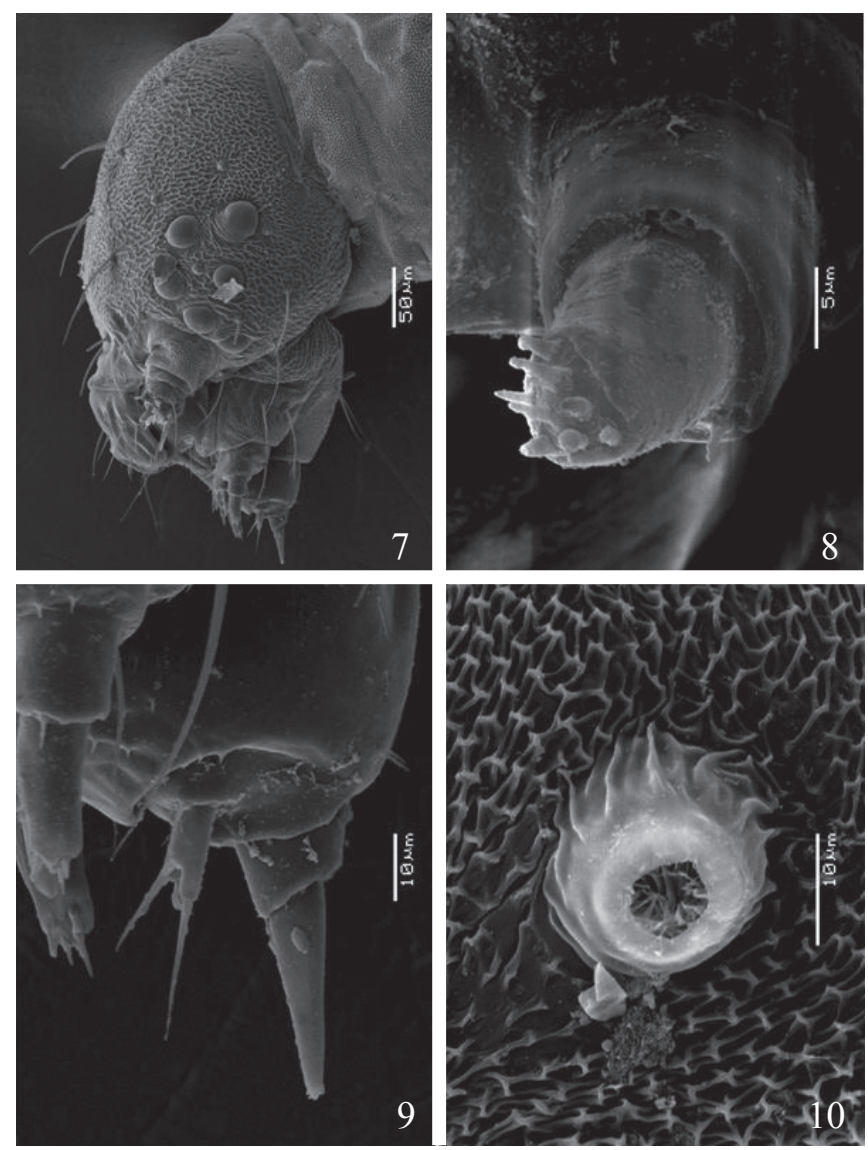

Figs. 7-10. Primeiro ínstar de Chrismopteryx undularia. 7, cabeça, vista lateral; 8, palpo maxilar; 9, fiandeira e palpo labial; 10, espiráculo protorácico.

8, 19) compostas por gáleas e palpos triarticulados. Lábio (Figs. 9, 17-18) com fiandeira cilíndrica, orifício de saída da seda no ápice; um par de pequenas cerdas próximas à base da fiandeira; palpos labiais dorsais à fiandeira, biarticulados, comprimento quase a metade da fiandeira, artículo basal cilíndrico, estreito e alongado, artículo distal pequeno, ambos com cerda no ápice.

Tórax (Figs. 10, 20, 22, 24-26, 28, 31). Tegumento finamente reticulado (Fig. 10); placa protorácica (Fig. 20) subretangular, com quatro pares de cerdas e três pares de poros, fenda mediana ausente, margens anterior e posterior sinuosas, margens laterais arredondadas; cerdas táteis com ápice em forma de coroa (Figs. 24-25), exceto SD1 e L2 no protórax, SV1 no metatórax e V1 nos três segmentos torácicos, que tem o ápice agudo (Fig. 22); espiráculo protorácico (Fig. 10) com peritrema circular. Três pares de pernas (Fig. 28) desenvolvidas com coxa larga e curta, com área triangular esclerotinizada na face anterior e faixa transversal esclerotinizada estreita na face posterior; trocânter reduzido na forma de estreita faixa entre a coxa e o fêmur; este e a tíbia subcilíndrica e alongada; tarso uniarticulado, subcônico, com pequena garra apical simples (Fig. 26); cerdas táteis de todos os artículos com ápice agudo, exceto TS3 plana e de ápice truncado (Fig. 26).

Abdome (Figs. 21, 23, 27, 29-31). Ornamentação do tegumento similar ao tórax; espiráculos circulares lateralmente nos segmentos A1-A8; larvópodos em A6 e A10, em A6 com uma placa esclerotinizada triangular na face lateral (Fig. 29), e A10 com duas placas esclerotinizadas, uma estreita ântero-lateral e outra larga póstero-lateral (Fig. 30); ganchos (Figs. 27, 29-30) mesoseriais variando em número de 18 a 20 para ambos os larvópodos; placa anal (Fig. 21) subtriangular, margem anterior com fenda profunda não pigmentada que alcança $2 / 3$ do comprimento da placa; placa subanal triangular; cerdas táteis com ápice em forma de coroa (Fig. 23), exceto SD2 em A1-A8, grupo SV e V1 em A6, SV1 e V1 em A7 e A8, V1 em A9, SD1, D2, L2, L3, PP1, SV1, SV3, SV4 e V1 em A10, que possuem ápice agudo.

Medidas. Largura média da cabeça $0,35 \mathrm{~mm}(0,34-0,36$ $\mathrm{mm})$; comprimento médio do corpo $5,58 \mathrm{~mm}(5,1-6,1$ $\mathrm{mm})$.

Duração. 5-6 dias.

Quetotaxia da cabeça (Figs. 11-12).

Grupo Adfrontal (AF). AF2 próximo ao vértice superior do frontoclípeo; poro AFa próximo da sutura adfrontal, mais perto de AF2 que de AF1.

Grupo Anterior (A). A1 dorsal ao alvéolo antenal, entre a sutura adfrontal e o estema 4; $\mathrm{A} 2$ dorsal à $\mathrm{A} 1 ; \mathrm{A} 3$ pósterodorsal à $\mathrm{A} 2$ e dorsal ao estema 2; poro Aa dorsal à A2.

Grupo Cefalodorsal (CD). CD2 mediana à linha que une $\mathrm{CD} 1$ e CD3; poro $\mathrm{CDa}$ lateral à linha que une $\mathrm{CD} 1 \mathrm{e} \mathrm{CD} 3$.

Grupo Clipeal (C). $\mathrm{C} 1$ e $\mathrm{C} 2$ próximas à margem ventral do frontoclípeo; $\mathrm{C} 1$ adjacente à sutura adfrontal; $\mathrm{C} 2$ entre $\mathrm{C} 1$ e a linha média do frontoclípeo.

Grupo Frontal (F). F1 próximo ao ponto médio entre a

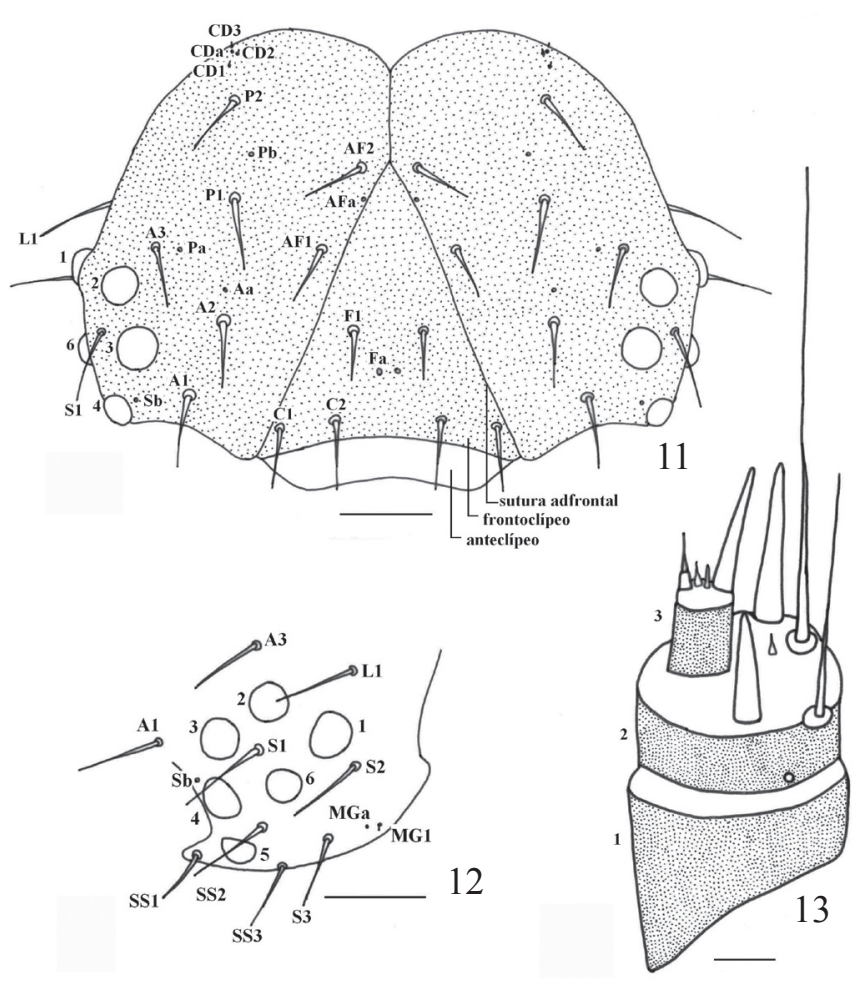

Figs. 11-13. Primeiro ínstar de Chrismopteryx undularia. 11, cabeça, vista anterior, escala: $0,05 \mathrm{~mm} ; 12$, área estematal, vista lateral, escala: $0,05 \mathrm{~mm}$; 13) antena, escala: $0,01 \mathrm{~mm}$. 

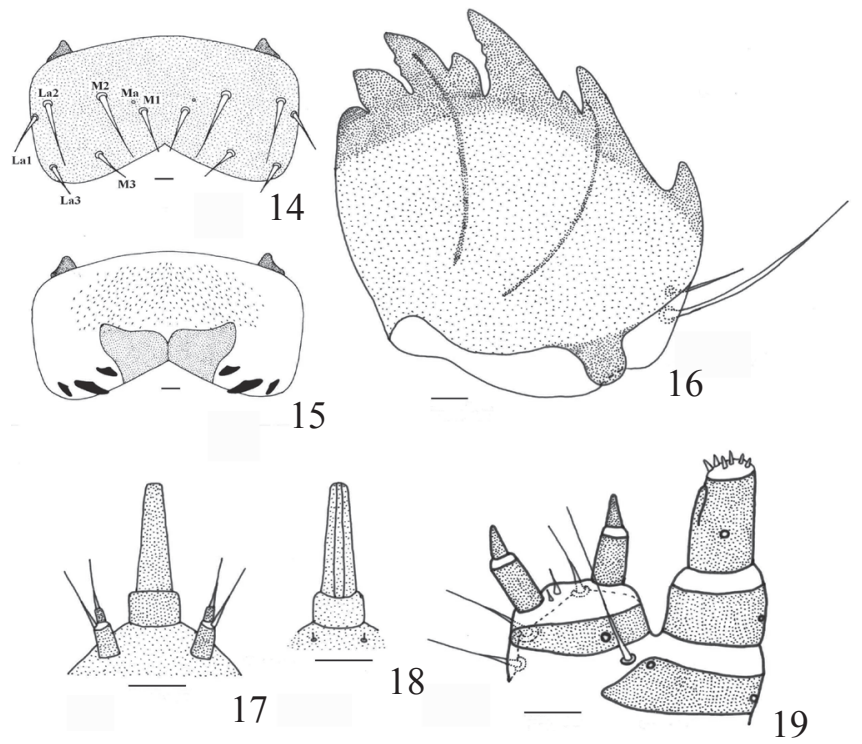

Figs. 14-19. Primeiro ínstar de Chrismopteryx undularia. 14, labro, vista anterior; 15 , superfície interna do labro; 16 , mandíbula; 17 , fiandeira e palpos labiais, vista dorsal; 18, fiandeira, vista ventral; 19, maxila. Escalas: 0,01 $\mathrm{mm}$.

sutura adfrontal e a linha média do frontoclípeo; poro $\mathrm{Fa}$ médio-ventral à F1.

Grupo Lateral (L). L1 dorsal ao estema 1; poro La posterior à L1.

Grupo Microgenal (MG). MG1 posterior à S3; poro MGa ântero-ventral à MG1.

Grupo Póstero-dorsal (P). P1 perto do ponto médio entre $\mathrm{L} 1$ e AF2; $\mathrm{P} 2$ dorsal à $\mathrm{P} 1$; poro $\mathrm{Pa}$ ventral à $\mathrm{P} 1$; poro $\mathrm{Pb}$ entre P1 e P2.

Grupo Estematal (S). S1 posterior ao estema 3; S2 posterior ao estema 1; poro Sa entre SS2 e S3; poro Sb entre estemas 3 e 4.

Grupo Subestematal (SS). SS1 ventral ao alvéolo antenal; SS2 entre estemas 5 e 6; SS3 póstero-ventral ao estema 5.

Cerdas e poros do labro (Fig. 14). Três pares de cerdas táteis (M1, M2, M3), M1 perto da linha média, M2 láterodorsal à $\mathrm{M} 1, \mathrm{M} 3$ látero-ventral à $\mathrm{M} 2$; três pares de cerdas laterais (La1, La2, La3), La1 próxima da margem lateral, La2 mediana-dorsal à La1, La3 mediana-ventral à La1 e próxima da margem ventral; poro Ma entre M1 e M2, dois poros entre M2 e M3.

Quetotaxia do tórax (Fig. 31).

Protórax. Onze pares de cerdas táteis (XD1, XD2, D1, D2, SD1, SD2, L1, L2, SV1, SV2, V1), quatro pares de proprioceptores (MD1, MV1, MV2, MV3) e três pares de poros. XD1 e XD2 próximas à margem anterior da placa protorácica; XD1 ântero-dorsal à XD2. D1 e D2 próximas à margem posterior da placa protorácica; D1 ântero-dorsal à D2. Grupo SD sobre pináculo elipsóide próximo à margem lateral da placa dorsal; SD1 ântero-ventral à SD2; SD1 alongada e de ápice agudo, quase duas vezes o comprimento de SD2. Grupo L em pináculo elipsóide ventral ao grupo SD e anterior ao espiráculo; L1 anterior à L2; L2 pequena e de ápice agudo, menor que $1 / 4 \mathrm{o}$ comprimento de L1. V1 pequena e de ápice agudo. Proprioceptores: anteriores à perna. Poros: dois póstero-ventrais a XD1 e um póstero-ventral a XD2.

Perna protorácica (Fig. 28). Coxa com oito cerdas táteis (CX1, CX2, CX3, CX4, CX5, CX6, CX7, CX8) todas com ápice agudo, CX1-CX5 na superfície anterior, CX6-CX8 na superfície posterior, nos extremos da faixa transversal esclerotinizada, CX3, CX5, CX8 pequenas. Trocânter com uma cerda tátil (TR1) pequena e três poros (TRa, TRb, TRc), cerda e poros na margem distal. Fêmur com duas cerdas táteis (FR1, FR2) alongadas de ápice agudo próximas da superfície mediana. Tíbia com seis cerdas táteis (TB1, TB2, TB3, TB4, TB5, TB6) alongadas com ápice agudo e um poro (TBa). Tarso com quatro cerdas táteis (TS1, TS2, TS3, TS4), TS1, TS2, TS4 alongadas e com ápice agudo, TS3 mais larga que as demais e com o ápice truncado; TS1 mais fina que as demais.

Meso e metatórax. Sete pares de cerdas táteis (D1, D2, SD1, SD2, L1, SV1, V1), seis pares de proprioceptores (MD1,
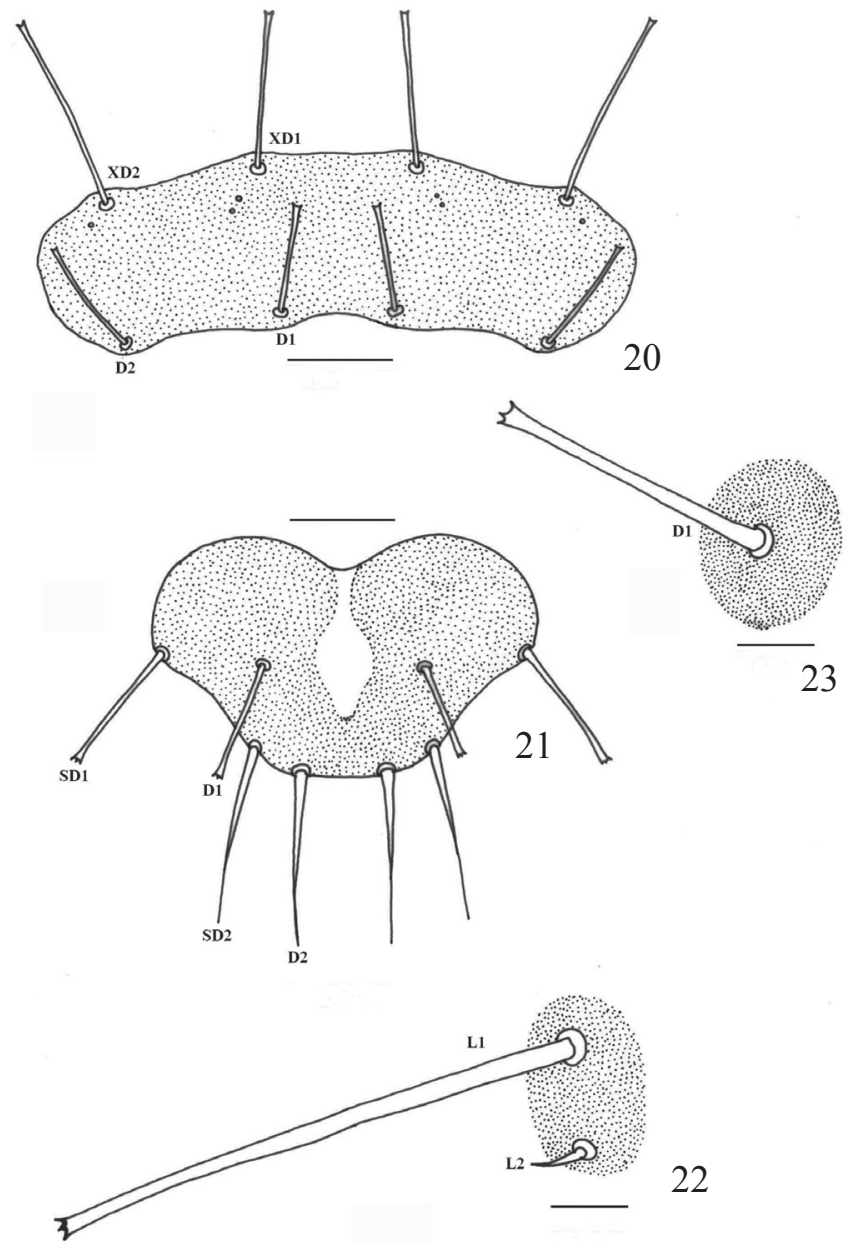

Figs. 20-23. Primeiro ínstar de Chrismopteryx undularia. 20, placa protorácica, escala: $0,05 \mathrm{~mm} ; 21^{\prime}$, placa anal, escala: $0,05 \mathrm{~mm}$; 22, cerda D1 do primeiro segmento abdominal, escala: $0,01 \mathrm{~mm} ; 23$, grupo $\mathrm{L}$ do protórax, escala: $0,01 \mathrm{~mm}$. 

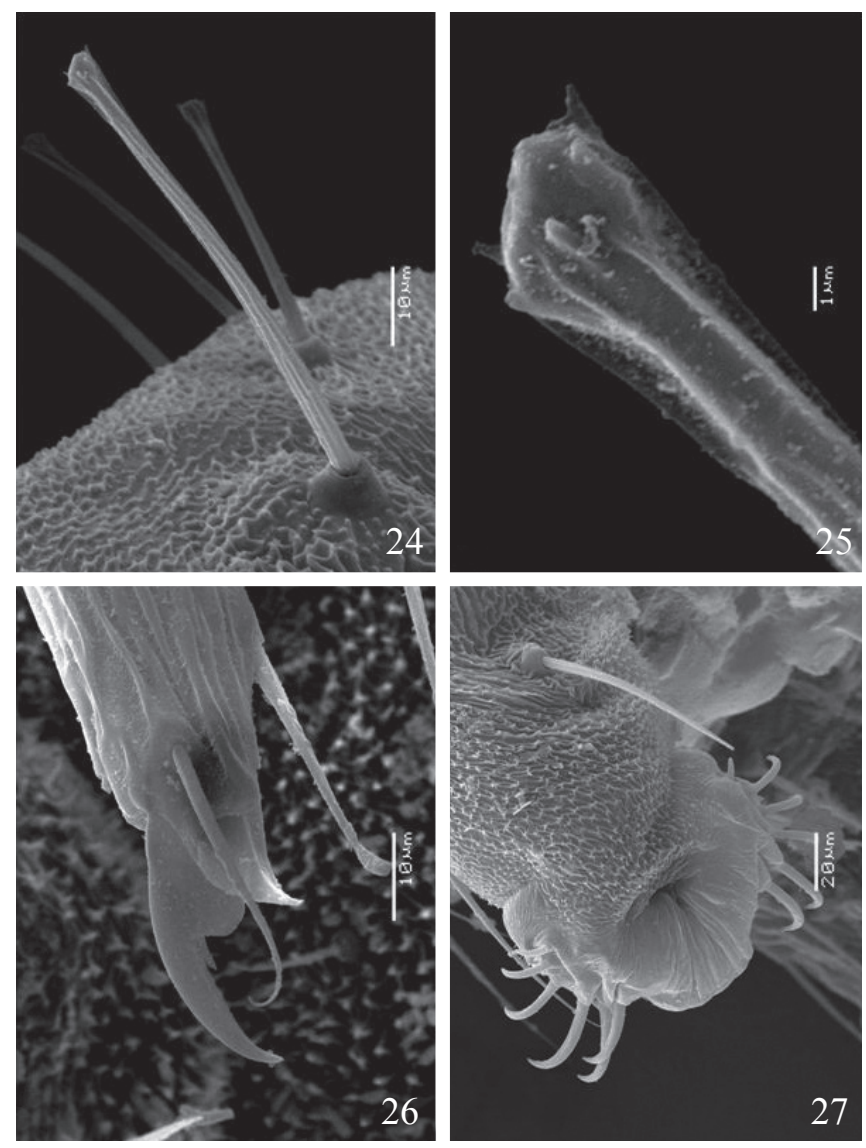

Figs. 24-27. Primeiro ínstar de Chrismopteryx undularia. 24, cerda D2 do mesotórax; 25, ápice da cerda D2 do mesotórax; 26, ápice do tarso; 27, ganchos do larvópodo do sexto segmento abdominal.

MSD1, MSD2, MV1, MV2, MV3); todas as cerdas táteis com o ápice em forma de coroa, exceto SV1 no metatórax e V1; SD2 e V1 não sobre pináculos, as restantes sobre pináculos circulares; D2 dorsal à SD2; SD1 ântero-ventral à SD2; L1 ântero-ventral à SD1; SV1 dorsal à inserção da perna. Proprioceptores: MD1 ântero-dorsal à D2; grupo MSD anterior à SD2; grupo MV anterior à perna. Quetotaxia das pernas meso e metatorácicas não difere daquela das protorácicas.

Abdome (Figs. 29-31).

A1. Nove pares de cerdas táteis (D1, D2, SD1, SD2, L1, L2, SV1, SV2, V1), dois pares de proprioceptores (MD1, MV3); todas as cerdas táteis alongadas, com o ápice em forma de coroa e sobre pináculo, exceto SD2 pequena, com ápice agudo e não sobre pináculo; D1 ântero-dorsal à D2; $\mathrm{SD} 2$ anterior à $\mathrm{SD} 1 ; \mathrm{L} 1$ póstero-dorsal ao espiráculo; L2 ântero-ventral à SD1; SV1 dorsal à V1; SV2 ântero-dorsal à V1. Proprioceptores: MD1 ântero-ventral à D1; MV3 ânterodorsal à V1.

A2-A5. Nove pares de cerdas táteis (D1, D2, SD1, SD2, L1, L2, SV1, SV2, V1), dois pares de proprioceptores (MD1, MV3); distribuição, forma e tamanho das cerdas similares à $\mathrm{A} 1$, exceto por $\mathrm{SD} 2$ póstero-ventral à $\mathrm{SD} 1$, L2 pósteroventral à SD1, L1 posterior ao espiráculo. Proprioceptores: similar à $\mathrm{A} 1$.
A6. Nove pares de cerdas táteis (D1, D2, SD1, SD2, L1, L2, SV1, SV2, V1), dois pares de proprioceptores (MD1, MV3); distribuição, forma e tamanho semelhantes aos segmentos abdominais precedentes, exceto o grupo SV sobre uma placa subtriangular esclerotinizada na superfície externa do larvópodo, V1 em pináculo circular na superfície mediana do larvópodo. Proprioceptores: MD1 similar à aquelas de A1A5; MV3 anterior à base do larvópodo.

A7. Oito pares de cerdas táteis (D1, D2, SD1, SD2, L1, L2, SV1, V1), dois pares de proprioceptores (MD1, MV3); grupos D, SD e L como em A6; SV1 e V1 com o ápice agudo, V1 não sobre pináculo. Proprioceptores: MD1 similar àquelas de A1-A6; MV3 ântero-dorsal à V1.

A8. Oito pares de cerdas táteis (D1, D2, SD1, SD2, L1, L2, SV1, V1), dois pares de proprioceptores (MD1, MV3); distribuição, tamanho e forma das cerdas similar à A7, exceto L1 póstero-ventral ao espiráculo. Proprioceptores: similar à A7.

A9. Seis pares de cerdas táteis (D1, D2, SD1, L1, SV1, V1), dois pares de proprioceptores (MD1, MV3); todas as cerdas táteis sobre pináculos e com o ápice em forma de coroa; exceto $\mathrm{V} 1$ com ápice agudo; D1 ventral à D2 e dorsal à $\mathrm{SD} 1$; L1 ventral à $\mathrm{SD} 1$ e dorsal à $\mathrm{L} 2$. V1 ventral à $\mathrm{L} 2$. Proprioceptores: similares à A8.

A10. Treze pares de cerdas táteis (D1, D2, SD1, SD2, PP1, L1, L2, L3, SV1, SV2, SV3, SV4, V1) e um poro (La); D1, D2, SD1, SD2 na placa anal, SD2, SD1, D2 na margem lateral, D1 póstero-dorsal à SD2; PP1, L1, L2, L3, SV1, SV2, SV3, SV4, V1 no larvópodo; L1, L2, L3 formando um triângulo na placa póstero-lateral do larvópodo; PP1 póstero-

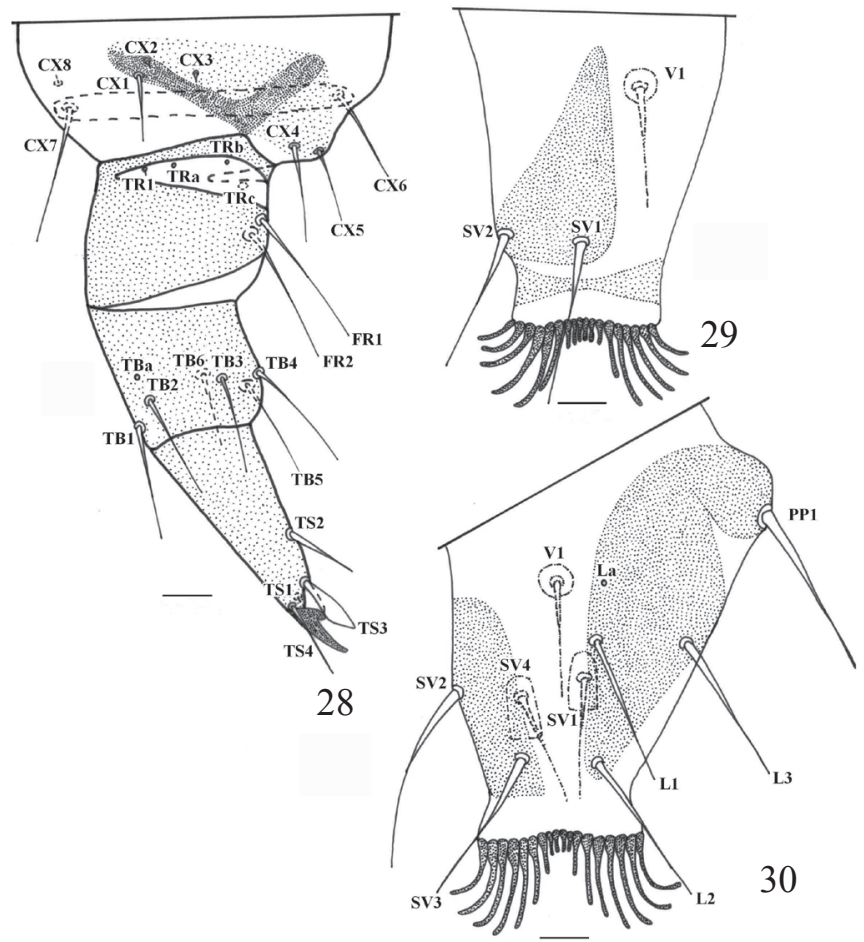

Figs. 28-30. Primeiro ínstar de Chirsmopteryx undularia. 28, perna do protórax; 29, larvópodo do sexto segmento abdominal; 30, larvópodo do décimo segmento abdominal. Escalas: 0,01 $\mathrm{mm}$. 

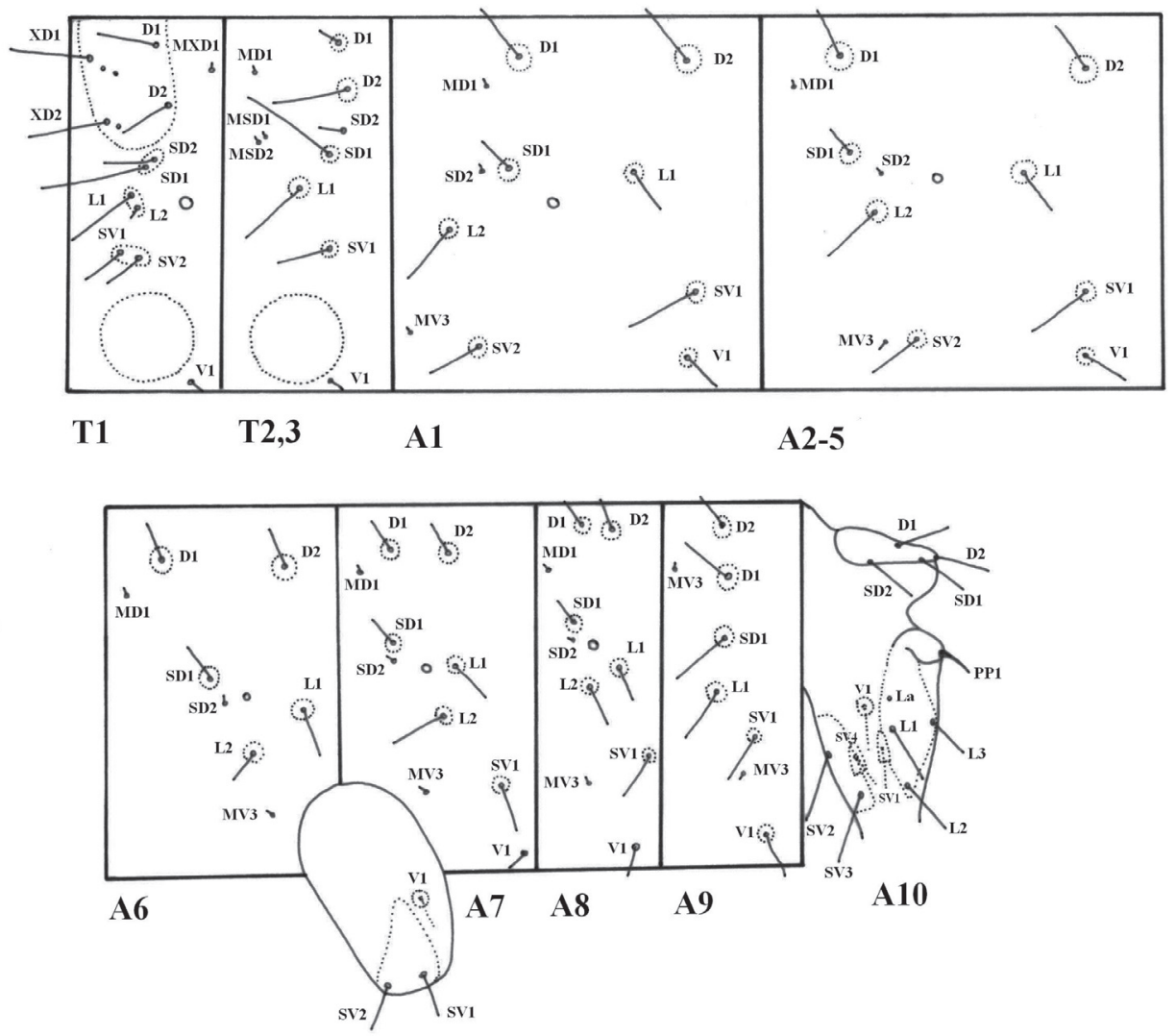

Fig. 31. Quetotaxia do tórax e do abdome do primeiro ínstar de C. undularia.

dorsal ao triângulo, perto da abertura anal; V1 em pináculo circular na face mediana do larvópodo, ántero-dorsal à SV1 e póstero-dorsal à SV4, estas em pináculos alongados; SV2 e SV3 na placa esclerotinizada ântero-lateral do larvópodo; poro La dorsal à L1.

Segundo ínstar. Cabeça castanho-clara com algumas manchas castanho-escuras; tórax e abdome variáveis, desde verde escuro até castanho; cerdas táteis da cabeça, tórax e abdome castanhas. Quetotaxia como na larva de quinto ínstar.

Medidas. Largura média da cabeça $0,57 \mathrm{~mm}(0,56-0,58$ $\mathrm{mm})$; comprimento médio do corpo $8,76 \mathrm{~mm}(8,3-9,2$ $\mathrm{mm})$.

Duração. 2-4 dias.

Terceiro ínstar. Coloração idêntica à da larva de segundo ínstar. Quetotaxia como na larva de quinto ínstar.

Medidas. Largura média da cabeça $0,79 \mathrm{~mm}(0,78-0,8$ $\mathrm{mm})$; comprimento médio do corpo $14,8 \mathrm{~mm}(13,9-15,6$ $\mathrm{mm})$.

Duração. 3-4 dias.

Quarto ínstar. Coloração idêntica à da larva de segundo ínstar. Quetotaxia como na larva de quinto ínstar.

Medidas. Largura média da cabeça $0,99 \mathrm{~mm}(0,92-1,04$ $\mathrm{mm})$; comprimento médio do corpo $14,8 \mathrm{~mm}(13,9-15,6$ $\mathrm{mm})$.

Duração. 3-4 dias.

Quinto ínstar. Cor como na larva de segundo ínstar. Cabeça
(Figs. 32-34) similar à larva de primeiro ínstar, exceto pela presença da linha ecdisial; antenas com artículo mediano cilíndrico e alongado (Fig. 33), comprimento quase duas vezes do artículo proximal; mandíbulas (Fig. 34) com bordo cortante serrilhado (11-12 dentes), cada uma das serrilhas também é serrilhada. Tórax similar à larva de primeiro ínstar, mas sem

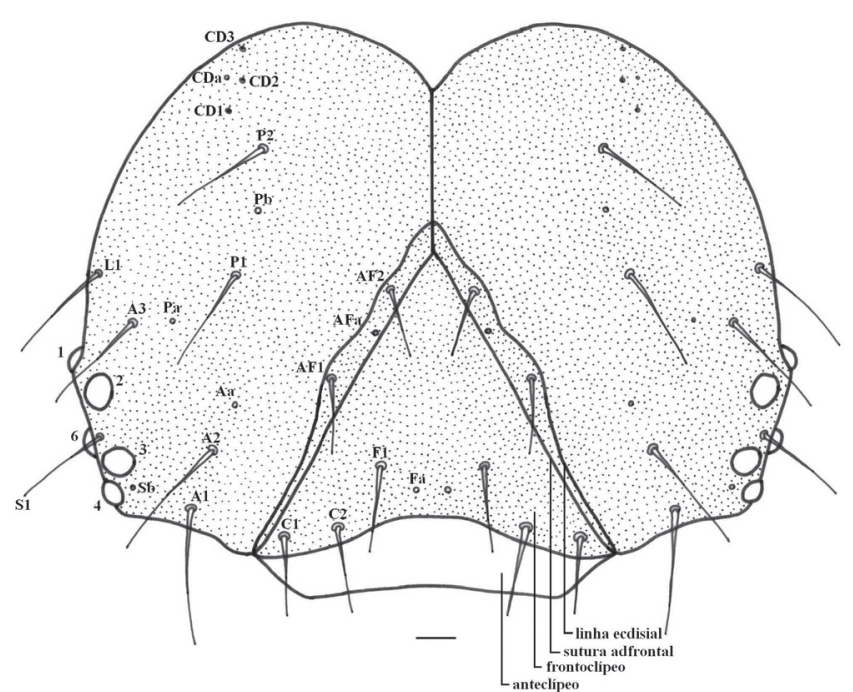

Fig. 32. Quetotaxia da cabeça do quinto ínstar de C. Undularia. Escala: 0,1 $\mathrm{mm}$. 


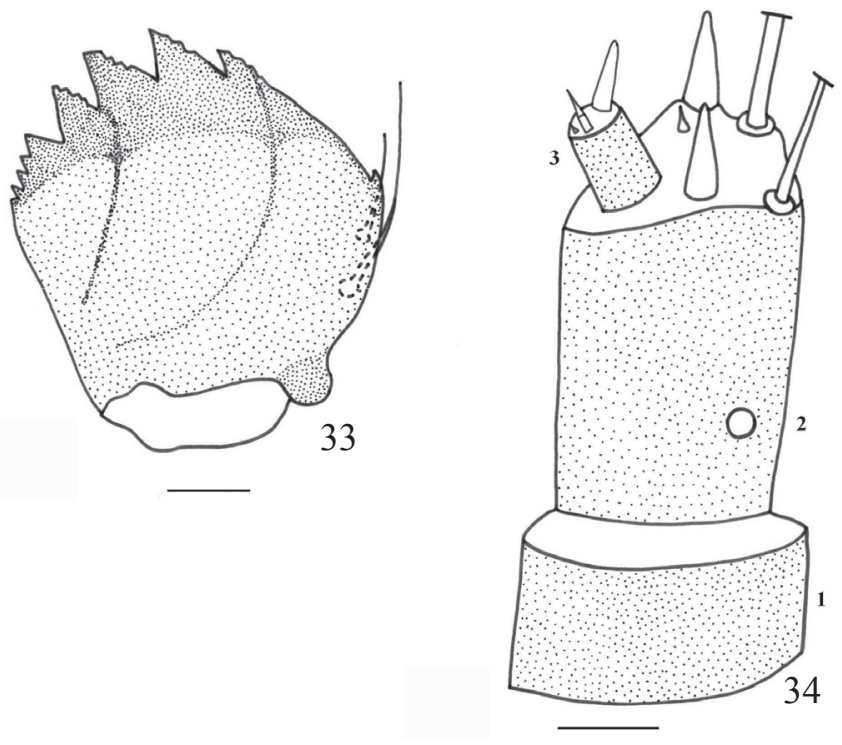

Figs. 33-34. Quinto ínstar de C. undularia. 33, mandíbula; 34, antena. Escalas $0,1 \mathrm{~mm}$.

pináculos; cerdas táteis alongadas e com o ápice agudo; placa protorácica pouco nítida; espiráculos elipsoidais. Abdome similar à larva de primeiro ínstar, mas sem pináculos; cerdas táteis alongadas e com o ápice agudo; espiráculos elipsoidais; placas dos larvópodos fracamente esclerotinizadas; ganchos variando de 36 - 40 nos dois pares de larvópodos; placa anal semicircular, margem anterior convexa no centro; placa subanal esclerotinizada.

Medidas. Largura média da cabeça 1,68 mm (1,58 - 1,78 $\mathrm{mm})$; comprimento médio do corpo $25,26 \mathrm{~mm}(23,8-28,1$ $\mathrm{mm})$.

Duração. 6-9 dias.

Quetotaxia. Cabeça (Fig. 32) similar ao primeiro ínstar, exceto que o grupo adfrontal AF fica entre a sutura adfrontal $\mathrm{e}$ a linha ecdisial; AF2 ventral ao vértice do frontoclípeo. Tórax (Fig. 35) similar ao primeiro ínstar, exceto o mesotórax com dois pares de cerdas táteis adicionais (L2, L3); no metatórax apresenta três pares de cerdas táteis adicionais (L2, L3, SV2). Abdome (Fig. 35) similar ao primeiro ínstar, exceto que os segmentos abdominais de A1-A5 e A7 apresentam dois pares de cerdas adicionais (L3, SV3); em A6 oito pares de cerdas táteis adicionais (L3, SV3-SV9); em A8 um par de cerdas táteis adicionais (L3); em A10 um par de cerdas táteis adicionais (EXL4) e um par de poros adicionais (Va).

Pupa (Figs. 36-42). Adéctica, obtecta e castanhoescura. Cabeça com tegumento liso; margem anterior da cabeça arredondada; antenas estreitas e compridas, base subapicalmente na cabeça, lateralmente delimitadas pelas asas mesotorácicas, ápice próximo à margem posterior de A4; frontoclípeo limitado posteriormente pelo labro; sutura epicranial diferenciada; olhos compostos delimitados dorsolateralmente pelas antenas, posteriormente pelas gáleas e as pernas protorácicas; gáleas no centro da região ventral da pupa, desde a margem posterior dos olhos compostos até o ápice das antenas.
Tórax com tegumento liso. Protórax visível láterodorsalmente; em vista dorsal com aspecto de uma faixa transversal estreita com os extremos laterais agudos, limitada anteriormente pelas antenas e o vértice, posteriormente pelo mesotórax; nos extremos laterais da margem posterior estão os espiráculos protorácicos; pernas protorácicas na face ventral, laterais às gáleas, posteriormente alcançam quase $2 / 3$ do comprimento das gáleas. Mesotórax maior que o protórax; dorsalmente evidenciado pelas asas mesotorácicas, ventralmente pelas pernas e as asas; pernas mesotorácicas laterais às pernas protorácicas, ápice coincidente com aqueles das antenas e gáleas. Metatórax visível em vistas dorsal e lateral; dorsalmente evidenciado como uma faixa transversal com a margem anterior côncava, asas metatorácicas projetadas posteriormente entre as asas mesotorácicas e os segmentos abdominais.

Abdome. Composto por dez segmentos; A1-A3 subretangulares em vista dorsal, lateralmente delimitados pelas asas metatorácicas; A4-A7 com forma de anel; A8-A10 fusionados, margem entre A8 e A9 fracamente diferenciada, margem entre A9 e A10 fracamente diferenciada na face ventral, porém diferenciada e sinuosa dorsolateralemente (Fig. 42); A10 dilatado lateralmente (Figs. 39-42), ápice cônico, cremaster (Fig. 42) composto por oito cerdas alongadas com ápice curvo, as duas centrais (D2) mais largas que as demais. Espiráculos de A1-A8 elípticos laterais; espiráculo de A1 oculto pelas asas metatorácicas; espiráculo A8 reduzido. Orifício anal (Figs. 39-40) ventralmente em A10, alongado e orientado longitudinalmente. Tegumento abdominal esculpido por depressões poligonais com lados levemente côncavos. A4 eA5 com uma faixa no terço posterior, ornamentada por bandas transversais esclerotinizadas. Orifício genital do macho (Fig. 40) na região médiano-ventral de $\mathrm{A} 9$, delimitado lateralmente por pequenos escleritos semirculares. Orifício genital da fêmea (Fig. 39) na região mediana-ventral de A8 e A9, não delimitado lateralmente por escleritos semicirculares.

Medidas. Largura média no terceiro segmento abdominal 4,2 $\mathrm{mm}(3,9-4,5 \mathrm{~mm})$; comprimento médio do corpo 14,32 $\mathrm{mm}(12,7-15,3 \mathrm{~mm})$.

Duração. 12-15 dias.

\section{DISCUSSÃO}

Esta é a primeira descrição de imaturos para uma espécie de Chrismopteryx e, provavelmente, seja a primeira a incluir quetotaxia da larva de primeiro ínstar para um Geometridae Neotropical. Adicionalmente, B. glabra é a primeira planta hospedeira conhecida para C. undularia e, ao mesmo tempo, a coleta de $C$. undularia na Província de Arica amplia sensivelmente a distribuição geográfica conhecida para esta espécie no território chileno, pois era conhecida somente da localidade-tipo.

O número de aberturas micropilares e o número de células da roseta micropilar são variáveis em ovos de $C$. undularia. A morfologia do ovo de C. undularia é similar ao descrito por Salkeld (1983) para espécies Neárticas de Xanthoroini e algumas de Hydriomenini, principalmente com relação 

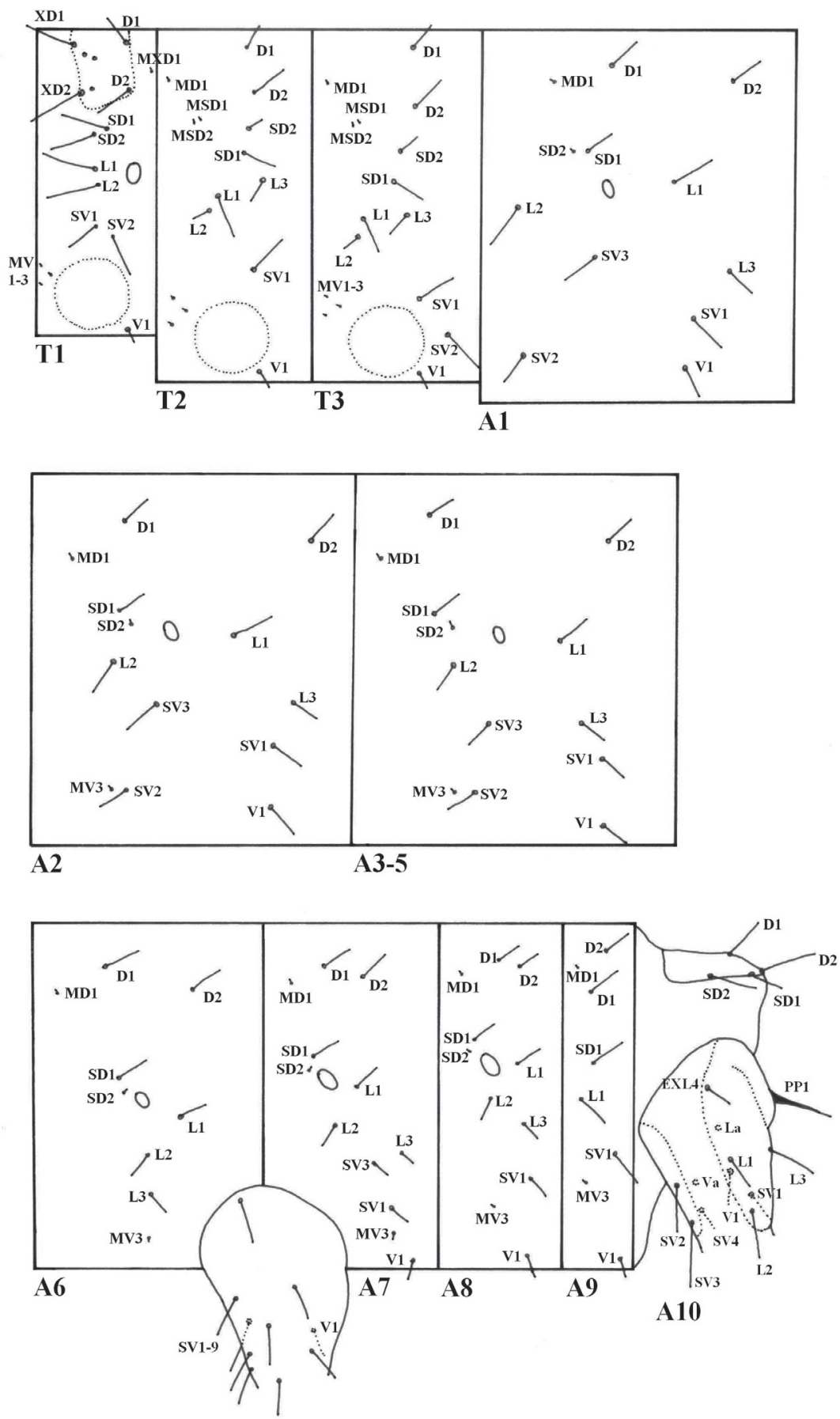

Fig. 35. Quetotaxia do tórax e do abdome do quinto ínstar de C. undularia.

ao cório esculpido com células poligonais fracamente desenvolvidas.

Algumas mudanças morfológicas associadas ao desenvolvimento ontogenético da larva foram observadas em C. undularia. Trabalhos prévios com espécies Neárticas (McGuffin 1963, 1973) e Paleárticas (Blaik \& Malkiewicz 2003) já indicavam variações na quetotaxia e morfologia das cerdas em outras espécies de Geometridae. Caracteres morfológicos que mudam entre os ínstares larvais de $C$. undularia são: linha ecdisial cefálica (presente no quinto ínstar), comprimento relativo do segundo artículo antenal, número e aspecto das serrilhas mandibulares, forma $\mathrm{e}$ comprimento relativo das cerdas do tórax e do abdome, número de cerdas em cada segmento do tórax e do abdome, e presença de pináculos. Especial atenção deve ser dada ao grupo SV em T3 e para as cerdas do grupo SV nos larvópodos de A6. No grupo SV de T3 é adicionada a cerda SV2. No larvópodo de A6 são nove as cerdas SV desde o segundo até o quinto ínstar. Numerosas cerdas SV no larvópodo de A6 são encontradas também a partir do segundo ínstar em espécies 


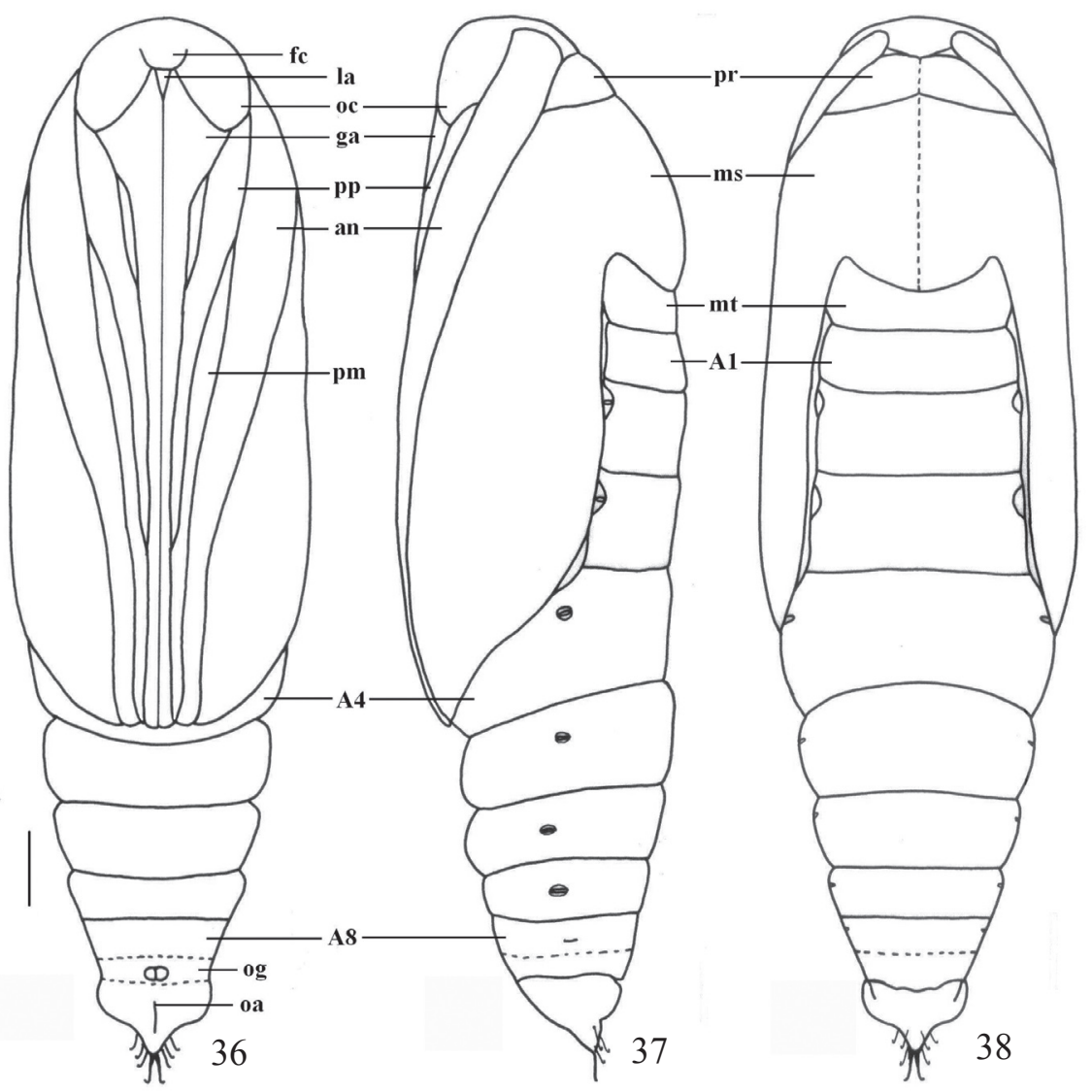

Figs. 36-38. Pupa de C. undularia. 36, vista ventral; 37, vista lateral; 38, vista dorsal. A: segmento abdominal; an: antena; fc: frontoclípeo; ga: gálea; la: labro; ms: asa mesotoráxica; mt: asa metatoráxica; oa: orifício anal; oc: olho composto; og: orifício genital; pm: perna mesotoráxica; pp: perna protoráxica; pr: protórax. Escala: $1 \mathrm{~mm}$

Neárticas de Pero Herrich-Schäffer (Ennominae) (McGuffin 1963), porém em número maior do que o observado em $C$. undularia.

Estudos sobre a morfologia externa dos imaturos de Chrismopteryx eram desconhecidos até a presente contribuição. O trabalho de McGuffin (1958) é a referência mais completa sobre larvas de Larentiinae, embora esteja restrita à fauna Neártica, e principalmente à morfologia da larva de último ínstar. As contribuições mais completas sobre os imaturos de Larentiinae neotropicais são as de Ibarra-Vidal \& Parra (1993) e Parra \& Ibarra-Vidal (2002), com descrições de ovo, larva de último ínstar e pupa de duas espécies de Eupithecia Curtis, 1825 (Larentiinae, Eupitheciini). Na chave de McGuffin (1958) para as tribos de Larentiinae, com base em caracteres morfológicos das larvas de último ínstar, a larva de C. undularia entra em Xanthorhoini e, além disso, as características morfológicas se ajustam bem à descrição dada para a tribo na mesma publicação. As breves descrições de larvas de primeiro ínstar apresentadas por McGuffin (1958) para espécies Neárticas de Xanthorhoini não permitem efetuar comparações morfológicas com a de C. undularia. Porém, em trabalho posterior, McGuffin (1973) descreve todos os imaturos das duas espécies norte-americanas de Rheumpatera Hübner, 1822 (Larentiinae, Hydriomenini); caracteriza as larvas de primeiro ínstar do gênero como tendo
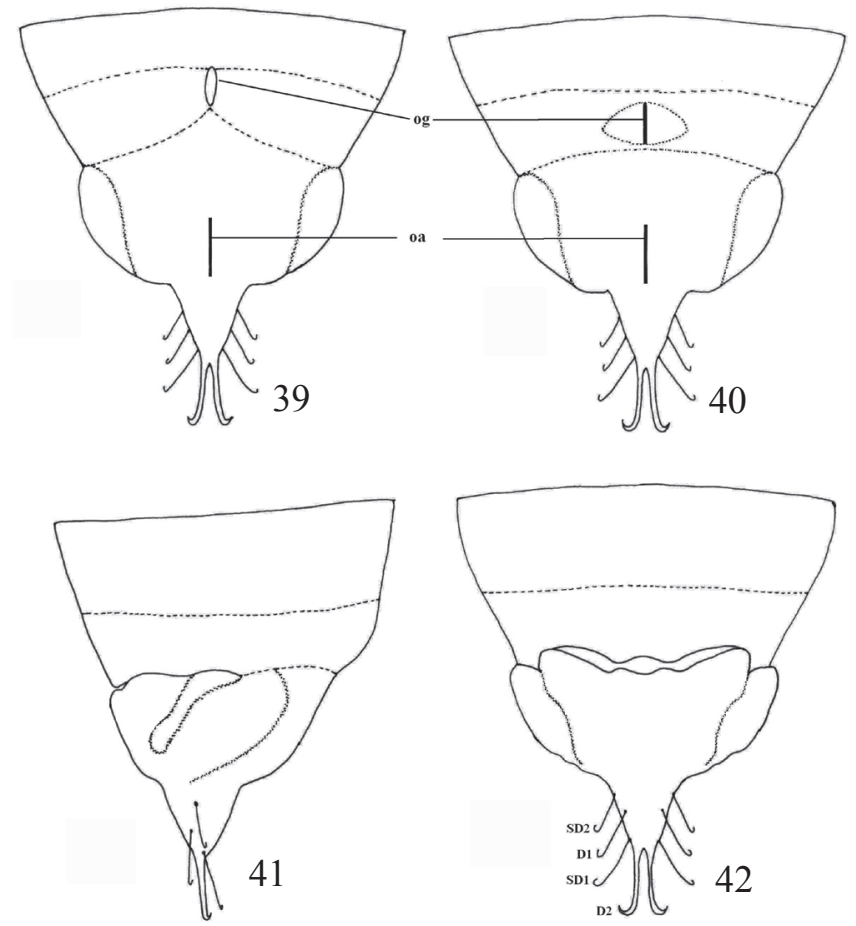

Figs. 39-42. Terminália pupal de C. undularia. 39, fêmea, vista ventral; 40, macho, vista ventral; 41, macho, vista lateral; 42, macho, vista dorsal. oa: orifício anal; og:orifício genital. Escala: $1 \mathrm{~mm}$. 
cerdas pontiagudas e capitadas, com um padrão de variação diferente do observado em $C$. undularia entre as cerdas de ápice agudo e as de ápice em forma de coroa. Na pupa, o cremaster destas espécies de Rheumaptera é similar ao de $C$. undularia, com as cerdas centrais nitidamente mais largas que as demais, embora este mesmo padrão morfológico esteja presente também em outros grupos de Larentiinae, como Eupithecia (Bolte 1990; Vargas \& Parra 2002, 2004; Vargas et al. 2002).

As mudanças morfológicas observadas neste estudo, associadas ao desenvolvimento ontogenético das larvas, principalmente relacionadas à quetotaxia, mostram que em estudos da morfologia externa do estágio larval é importante, sempre que possível, incluir material de diferentes ínstares.

Agradecimentos. Os autores são gratos à Dra. Danúncia Urban (Universidade Federal do Paraná, Curitiba, Paraná, Brasil), ao Dr. Gilson R. P. Moreira (Universidade Federal do Rio Grande do Sul, Porto Alegre, Rio Grande do Sul, Brasil) e ao Dr. Manoel Martins Dias (Universidade Federal de São Carlos, São Carlos, São Paulo, Brasil) pelas sugestões sobre resultados preliminares do trabalho. Ao pessoal do Laboratório de Microscopía Electrónica, Universidad de Concepción (Concepción, Chile). Ao Dr. Marcelo Duarte e aos avaliadores pelas sugestões sobre a versão inicial do manuscrito. Ao projeto DIEXA-UTA 9710-08.

\section{REFERÊNCIAS}

Blaik, T. \& A. Malkiewicz. 2003. Morphology of larval and pupal stages of Isturgia roraria (Fabricius, 1777) (Lepidoptera: Geometridae). Annales Zoologici 53: 245-258.

Bolte, K.B. 1990. Guide to the Geometridae of Canada (Lepidoptera). VI Subfamily Larentiinae. 1 Revision of the genus Eupithecia. Memoirs of the Entomological Society of Canada 151: 1-253.

Choi, S. W. 1997. A phylogenetic study on genera of Cidariini from the Holarctic and the Indo-Australian areas (Lepidoptera: Geometridae: Larentiinae). Systematic Entomology 22: 287-312.

Duarte, M. ; R. K. Robbins \& O. H. H. Mielke. 2005. Immature stages of Calycopis caulonia (Hewitson, 1877) (Lepidoptera, Lycaenidae, Theclinae, Eumaeini), with notes on rearing detritivorous hairstreaks on artificial diet. Zootaxa 1063: 1-31.

Gaston, K. J.; M. J. Scoble \& A. Cook. 1995. Patterns in species descriptions: a case study using Geometridae (Lepidoptera). Biological Journal of the Linnean Society 55: 225-237.

Heppner, J. 1991. Faunal regions and the diversity of Lepidoptera. Tropical Lepidoptera 2, Supplement 1: 1-85.

Herbulot, C. 1993. Deux noveaux Cyclophora du Pérou (Lepidoptera, Geometridae). Nouvelle Revue d'Entomologie (N.S.) 10: 55-58.

Hinton, H. E. 1946. On the homology and nomenclature of setae of lepidopterous larvae, with some notes on the phylogeny of Lepidoptera. Transactions of the Royal Entomological Society of London 97: $1-37$.

Ibarra-Vidal, H. \& L. E. Parra. 1993. Descripción de los estados preimaginales y aspectos de la historia natural de Eupithecia horismoides Rindge, 1987 (Lepidoptera, Geometridae), perforador del pecíolo del pangue (Gunnera tinctoria). Revista Chilena de Entomología 20: 35-41.

Landry, B. \& F. H. Rindge. 1995. Additions to the Geometridae (Lepidoptera) of the Galápagos Islands, Ecuador, including a new species of Eupithecia. American Museum Novitates 3118: 1-10.

Mackay, M. R. 1968. About lepidopterous immatures. Canadian Entomologist 100: 337-240.

Marconato, G. \& M. M. Dias. 2004. Estágios imaturos e bionomia de Cyclomia mopsaria Guenée (Lepidoptera: Geometridae). Revista Brasileira de Entomologia 48: 1-8.

McGuffin, W. C. 1958. Larvae of the Neartic Larentiinae (Lepidoptera: Geometridae). Canadian Entomologist, Supplement 8: 1-104.

McGuffin, W. C. 1963. The immature stages of the Canadian species of Pero Herrich-Schaeffer (Lepidoptera: Geometridae). Canadian Entomologist 95: 1159-1167.

McGuffin, W. C. 1973. The Rheumaptera of North America (Lepidoptera: Geometridae). The Canadian Entomologist 105: 383-398.

Parra, L. E. \& H. Ibarra-Vidal. 2002. A new species of Eupithecia (Lepidoptera: Geometridae) from the Juan Fernández Islands. Annals of the Entomological Society of America 95: 9-15.

Rindge, F. H. 1973. The Geometridae of the Galapagos Islands. American Museum Novitates 2510: 1-31

Salkeld, E. H. 1983. A catalogue of the eggs of some Canadian Geometridae (Lepidoptera), with comments. Memoirs of the Entomological Society of Canada 126: $1-27$.

Scoble, M. J. 1995. Lepidoptera. Form, function and diversity. The Natural History Museum, Suffolk, $404 \mathrm{p}$.

Scoble, M. J. 1999 (ed.). Geometrid moths of the world: A catalogue (Lepidoptera, Geometridae), v. 1 and 2, CSIRO Publishing and Apollo Books, Steenstrupia, 1016 p. (+129 p. of index).

Scoble, M. J. \& M. Krüger. 2002. A review of the genera of Macariini with a revised classification of the tribe (Geometridae: Ennominae). Zoological Journal of the Linnean Society 134: 257-315.

Sihvonen, P. 2005. Phylogeny and classification of Scopulini moths (Lepidoptera, Geometridae, Sterrhinae). Zoological Journal of the Linnean Society 143: 473-530.

Stehr, F. W. 1987. Geometridae (Geometroidea), p. 502-507. In: F. W. Stehr (Ed.), Immature Insects. Vol. 1. Dubuque, Kendall/Hunt Publishing Company, $975 \mathrm{p}$.

Vargas, H. A. \& L. E. Parra. 2002. Notas sobre Eupithecia atacama (Vojnits) (Lepidoptera: Geometridae). Idesia 20: 27-33.

Vargas, H. A., L. E. Parra, H. E. Vargas \& D. E. Bobadilla. 2002. Aspectos biológicos de Eupithecia sibylla Butler, 1882 (Lepidoptera: Geometridae). Gayana 66: 103-106.

Vargas, H. A. \& L. E. Parra. 2004. Una nueva especie de Eupithecia Curtis (Lepidoptera: Geometridae) del extremo norte de Chile. Revista Chilena de Historia Natural 77: 485-490. 